\title{
The Application of Task-driven Teaching Mode in the Course of Foreign Trade Documents Practice
}

\author{
Xiudan HUANG \\ Liaoning Economic Vocational Technological Institute, \\ Shenyang, China \\ e-mail: 459286694@qq.com
}

\begin{abstract}
This The practice of foreign trade documents is the core curriculum of international trade practice. It has characteristics of practical and operational. It is difficult to cultivate the applied talents to meet the positions of foreign trade documents by relying on the traditional teaching modes. The application of task driven teaching methods, transforming the teacher-oriented teaching methods into teacher-oriented and student-oriented teaching methods, which course content with professional post ability are associated, can improve the students' vocational skills and employability.
\end{abstract}

Keywords-foreign trade documents practice; task-driven teaching methods

\section{INTRODUCTION}

Task-driven pedagogy refers to the whole process of teaching to complete the specific task as a clue to the teaching content implied in the design of each task. In the completion of the task training students to self-learning and mutual ability in the meanwhile, thus guiding them to discover, think and find ways to solve problems, and build their own knowledge and skills. "Foreign trade documents practice" course is mainly to deal with foreign trade business and settlement process of the various documents. It is a professional and practical discipline, and it is the main course of international trade practice in teaching. This skill and practical course has a strong appeal to students with today's increasing emphasis on striking ability and adaptability to the workforce. The traditional "foreign trade document practice" teaching mode, including teaching materials are arranged so that students can understand theories and methods, but the students are still more vague with how to use foreign trade documents, according to international practice, to deal with foreign trade business, since the course involved a large number of business processes and various treatments with of the documents under specific circumstances. Actively attempt to reform the teaching methods, change the traditional teaching mode and building the import and export trade projects as the main line is crucial. According to the task driven mode of import and export trade settlement documents required for the content, teachers shall build the curriculum system with task module as center. Combining Teachers' guidance and students' study as one, cultivate the practical ability of students. Transforming "to me to learn" to "I want to learn", to effectively improve the quality of teaching, so that students have the ability to comprehensive operation of foreign trade documents, thus to meet the needs of foreign trade industry.

\section{THE APPLICABILITY OF TASK-DRIVEN TEACHING METHOd IN Foreign TRADE DOCUMENTS PRACTICE COURSE}

From all international trade practice in teaching content, not all courses are suitable for applications of task driven teaching mode, that depends on if curriculum content can be reflected by some tasks, the task itself should be directly related to enterprise actual production process or commercial business activities which has a certain practical value.

From the point of teaching content, different course content may be suitable for one or several different teaching methods. Foreign trade documents practice course introduces the filling and operation of relevant documents involved in the foreign trade business activities, including contract, letter of credit, invoice, packing list, bill of lading, certificate of origin, insurance policy, bill of exchange and other relevant documents. These documents are throughout the whole international trade business process. Therefore, it can be said that trade documents are the medium of international trade activities. Usually, from trade negotiations of buyers and sellers, signing the contract, to the goods delivery of one side, the payment of the entire process of delivery of the other side, every link has corresponding documents need to be made out, handed over and delivered, to meet the requirements of all parties and urge the enterprises complete import and export business. In most of the import and export trade, buyers and sellers treat documents as a basis for payment of delivery, so the documents are closely related to successful import and export business of the enterprise and access to a certain economic benefits. The whole process of documents filling and delivery is the whole process of international trade business implementation. Therefore, in foreign trade documents practice course, "unity in study and work" task-driven teaching model is mainly used. With appropriate cases to guide the organization of teaching, the teaching purpose will be explicit and the teaching veins will be clear, which plays a multiplier effect with half the effort. 


\section{Task-Driven Teaching Method IN The COURSE OF Foreign TRAde Documents Practice}

\section{A. Define the Task.}

In task-driven teaching, determination of task is the key, which concerns the success or failure of the teaching method. Therefore, the choice and determination of the task and the way of proposing must be carefully considered. First of all, the task should be operational, inoperable task is unable to complete. Second, the task should be coherent. The construction of the knowledge system is based on a series of coherent knowledge points, new knowledge learning is based on the accumulation of previous knowledge. During the learning of new knowledge, students have reviewed the previous knowledge, which consolidates the learning effect. Third, analyze curriculum objectives, students' foundation and interest, establish current learning subject-related learning situation as real as possible, to guide students start the study with real tasks. The creation of the situation can intuitively and effectively stimulate students' imagination, arouse students' existing knowledge and experience, so as to adapt to the learning of new knowledge and skills. For example, in foreign trade documents practice course, the trade process of foreign trade documents in actual business is presented through cases. With a comprehensive foreign trade business process as the background, set a foreign trade role and arrange all the tasks under his situation. Take the bill of lading as an example, change the past order of simply introducing concept, effect and content, instead put forward the task according to the business requirements in the situation, that is, how to complete the delivery task using the transport documents according to the contract and the letter of credit.

\section{B. Analyze the Task.}

Implementation of task driven teaching method is different from conventional teaching methods. Most of the conventional teaching methods are in the form of one-to-one or one-to-many, but task-driven teaching method is team working. After the task is presented, the students form a team every 4-5 people, analyze the tasks, describe the understanding of the task individually, fully discuss the tasks and make clear division of work. With the teacher's inspiration and help, students analyze the task, and produce a series of sub-tasks, among them they should find out where new knowledge is needed and where previous knowledge need to be applied. So that students can understand the goal of learning, their enthusiasm of learning new skills is mobilized, which helps students form correct thinking and learning methods of solving problems. As for the above task, with specific analysis, result in two sub-tasks, how should the clerk book space in accordance with the shipping terms and manage the transport matters; what documents will be involved in the transport business and how to fill the documents. Then teachers should help the students analyze what knowledge is required for both tasks.

\section{Complete the Task.}

After the task analysis phase, to complete the task, students need to determine the methods, required knowledge points both previous and new, the way to present the task, etc., after the discussion with the team members. During the process, teachers can provide relevant clues or resources, such as courseware, and also let students look up books or related information, organize internal discussion and communication and find out the solution. It not only cultivate the students' interest in learning, but also cultivate the students' cooperation spirit of working with others. In this process, teachers can inspect or participate in a group to check on the students' work. On the one hand, the problems during the completion of the task can be found, which need teachers' guidance, on the other hand, the achievement of learning objectives can be known, making the completion of the task and learning objectives unified. For the two sub-tasks above, students should analyze again the terms of the contract and the letter of credit, thinking that what request is made for the clerk to manage transportation and the requirements of relevant international practices on transport matters and documents, then look up booking process, and further study the process and the delivery of documents. In this process, the relevant knowledge of marine bill of lading, such as the concept, effect, content and filling can be clear. Through the analysis, exploration and completion of the task, students not only master the knowledge and skills, but also understand the various foreign trade business situation and know how to deal with documents according to international practice, which extends the students' thoughts and ideas. That is, not only know, but also know why.

\section{Assessment and Induction.}

There must be an effective and reasonable evaluation system to assess the effect. This system includes evaluation criteria, evaluation categories, evaluation methods, evaluation feedback etc. Assessment is the comments of teachers on students' assignment. Teachers excavate students' sparkles, point out deficiency and summarize the rules and skills according to the teaching tasks and students' learning conditions. Details are as follows, students upload the assignment in the form of word document to teacher's computer through LAN of international trade training room, teacher displays the assignment in the class by multimedia and summarizes the advantages and disadvantages. From the pre-class preparation, the organization of the teaching process to the final Q \& A and summary, the teacher's leading role is fully reflected; from accepting the assignment, cooperation, completion to analyzing the gain and loss, the students' main role is fully embodied. The whole teaching process unifies teaching, learning and doing, ensuring good teaching results. 


\section{TASK DESIGN IN THE TASK DRIVEN TEACHING APPROACH}

\section{A. Task Design Must be Clear and Specific.}

The task of "task-driven" teaching should be needed in actual professional activities and meaningful, guide the students to analyze and solve the problem multi-dimensionally by providing various clues analysis. The goal of the task must be clear, guiding students to get learning materials purposefully in certain circumstances, and strengthen students' confidence and perseverance of further exploration. For instance, bills of exchange are often used for settlement, the task can be set as, what kind of bills of exchange should be used in different settlement ways and how to fill them; create settlement situations like letters of credit, collection, demand draft, etc., guide students look up relevant information and practice to complete the task.

\section{B. Task Design Should be for All Students yet Individualised.}

Task is the method for students to learn. When designing the task, teachers must give full consideration to the students' existing level of knowledge and their cognitive competence, Individualized and step by step. In the overall goal framework, teachers should divide each learning module into small and easy tasks that reflect the overall learning goal. In the design, knowledge points cannot be involved too much, the operability of the task must be focused on, and the scale of the task should be small. Take "filling packing list" as an example, first to provide the required materials for the packing list, followed by presenting letters of credit, contracts and other information, finally asking the students to find the right content to complete the filling task.

\section{Task Design Should be Conducive to Students' Inquiry and Analysis.}

After the task is given, instead of rushing to answer, teachers should lead the students to analyze the task first, let them discuss and ask questions, then give appropriate guidance to analyze and solve the questions. Dealing with the problems themselves can cultivate the ability to solve problems of the students using existing knowledge and skills, attract attention to the problems and enhance the class effect. For example, in the letter of credit the drawee of bills of exchange should be a banker, but in the assignment, the "drawee (payee)" is the importer. Guiding the students to look up relevant practice can make it clear that in the letter of credit the drawee cannot be the importer, otherwise bills of exchange will fail. Only in the documents of the letter of credit, the beneficiary's payment guarantee is weakened; meanwhile, let students think the drawee of bills of exchange on collection basis. In this way, the filling of the items will be very clear for the students.

\section{V.THE ASSESSMENT OF TASK-DRIVEN TEACHING MODEL}

The focus of task-driven teaching method is the process rather than the results. The process assessment is completed when students complete the task of each module as planned. After the completion of each module, teachers will make a stage assessment according to the key points of the program. Specifically, the assessment of the course is divided into three parts: part one is the usual performance, including classroom questioning, homework, etc., accounting for $20 \%$ of the total grade; part two is the practice part, mainly filling specific documents, accounting for $30 \%$ in test of each unit; part three is the comprehensive operation part, mainly examining comprehensive abilities of students, accounting for $50 \%$ in the final exam. This assessment method changes the traditional way that evaluates students with only one test score, and it is welcomed by the majority of students.

\section{SUMMARY}

The key problem of task-driven teaching method is to place students in real subject position. In the teaching process of "foreign trade document practice" course, teacher shall take the job capability of foreign trade document business as the starting point, with foreign trade as the main line, for the implementation of the whole business process, through simulation of the specific business documents. Performing the task-driven teaching mode, in which students will complete the task, can arouse their enthusiasm and creativity of their learning, cultivate students' ability of autonomous learning, and lay a solid foundation for internships and future career.

\section{ACKNOWLEDGMENT}

The research is one of project achievements that belongs to 2017 annual project of economic and social development granted bysocial science in liaoning province association. The title is the strategy research on cross-border e-commerce development in liaoning province. The project number is 2017LSLKTZD-009.

\section{REFERENCES}

[1] Zhang Zhi-jun. Further Students' Reflective Learning with the Task-driven Method $[\mathrm{J}]$. «Commercial Technology \& Vocational Education» 2010-9.

[2] Yang Jihong, Kong Yonghong. Research on "Behavior - oriented, Task - based" Teaching Mode[J]. «Journal of Shanxi adio \& TV University» 2011-1.

[3] Zhang Yong-hua, Xia Ming-hui, Chen Sa. Application of Task-Driven Method in the Teaching of Accounting Computerization[J]. «Modern Computer» 2009-6.

[4] Liu Lintao, Research and Practice of Task-driven Teaching Model 2014, n12J. Modern Education Science. pp45-47. 